presentation of mental ill health is reflected in the pattern of consultation. Patients tend to pass through different health care 'fitters' before they reach psychiatric clinics and hospitals. According to Goldberg \& Huxley (1992), almost two-thirds of patients with psychiatric symptoms attend only their general practitioner, and only $50 \%$ of those would be recognised as having a psychiatric disorder.

In this context, traditional and religious healers play a

Traditional and religious healers play a major role in primary psychiatric care in Egypt. They deal with minor neurotic, psychosomatic and transitory psychotic states using religious and group psychotherapies, suggestion and devices such as amulets and incantations. major role in primary psychiatric care in Egypt. They deal with minor neurotic, psychosomatic and transitory psychotic states using religious and group psychotherapies, suggestion and devices such as amulets and incantations (0 kasha, 1966). It was estimated that $60 \%$ of out-patients at the university clinic in C airo, which generally serves people from low socio-economic classes, have been to traditional healers before attending a psychiatrist (0 kasha $\&$ Hassan, 1968). In rural areas, community care is implemented without the need for health care workers. Egyptians, especially those living in the countryside, have a special tolerance of mental disorders and an ability to assimilate those with a chronic mental illness. For example, these patients, and those with mild or moderate learning disabilities, may cultivate crops along with, and under the supervision of, family members.

Thus, the real challenge for mental health professionals is the first filter, that is, patients acknowledging their mental health problems. H owever, this challenge cannot be met without a reorganisation of both the health-providing structures and the approach to medical education and training. The latter cannot be systemically tackled without the guidance of action-oriented and policy-oriented research.

\section{References}

Baasher, T. (1975) The Arab countries. In World History of Psychiatry (ed. J. G. Howells), pp. 547-578. N ew York: Bruner/Mazel.

Buergel (1975) Der Mufarrih an-nafs des Ibn Cladi Ba'albakk, ein Lehrbuch der Psychohygiene aus dem 7. Jahrhundert der $\mathrm{H}$ ijra. In Proceedings of the Sixth Congress of Arabic and Islamic Studies (ed. F. Rundgren), p. 204. Leiden.

Dols, M. W. (1992) In Majnun: The Madman in Medieval Islamic Society (ed. D. E. Immisch), p. 133. O xford: Clarendon Press.

Goldberg, D. P. \& Huxley, P. (1992) Common Mental Disorders: A Biosocial Model. London: Routledge.

Ministry of $\mathrm{H}$ ealth (1998) Statistics. Cairo: Ministry of $\mathrm{H}$ ealth.

$\mathrm{N}$ ational Information Centre (1997) Statistical Yearbook. Cairo: $\mathrm{N}$ ational Information Centre.

O kasha, A. (1966) A cultural psychiatric study of El-Zar cult in U.A.R. British Journal of Psychiatry, 112, 1217-1221.

0 kasha, A., Kamel, M. \& Hassan, A. H. (1968) Preliminary psychiatric observations in Egypt. British Journal of Psychiatry, 114, 949-955.

0 kasha, A. \& Karam, E. (1998) Mental health services and research in the Arab world. Acta Psychiatrica Scandinavica, 98, 406- 413.

O kasha, A., Seif El-Dawla, A., Khalil, A. H., et al (1993) Presentation of acute psychosis in an Egyptian sample: a transcultural comparison. Comprehensive Psychiatry, 34, 4-9.

World Health O rganization (1996) Recommendations for M ental Health Services. Geneva: WHO.

\title{
Italian psychiatry - 25 years of change
}

\section{Angelo Fioritti ${ }^{1}$, Mariano Bassi and Giovanni de Girolamo ${ }^{3}$}

1Direttore Programma Salute Mentale e Dipendenze Patologiche, Azienda USL Rimini, via Coriano 38, 47900 Rimini, Italy, email afioritti@ausIrn.net; Elected President of the Italian Society for Addiction Psychiatry (Società Italiana Psichiatria delle Dipendenze - SIPD)

2Direttore Dipartimento Salute Mentale, Azienda USL Città di Bologna; Vice President of the Italian Society of Psychiatry (Società Italiana di Psichiatria - SIP)

${ }^{3}$ Dipartimento Salute Mentale, Azienda USL Città di Bologna; formerly responsible for the National Mental Health Project, National Institute of Health (Progetto Nazionale Salute Mentale, Istituto Superiore di Sanità), Rome

\begin{abstract}
talian psychiatry is probably more debated than known in the international arena. Law 180 of 1978, which introduced a radical community psychiatry system, has drawn worldwide attention and debate, with comments ranging from the enthusiastic to the frankly disparaging (Mosher, 1982; Jones et al, 1991). More recently, this interest was marked by a well-attended symposium 'Lessons Learned from Italian Reforms in Psychiatry' held at the 2003 annual meeting of the Royal College of Psychiatrists in Edinburgh.

$H$ istorical analyses of how the reform movement took momentum, produced a law and how it was enacted can be found elsewhere (Perris \& Kemali, 1985; Saraceno \& Tognoni, 1989; Mangen, 1989; Fioritti et al, 1997). In this
\end{abstract}

article we try to outline the general social context in Italy, its health and psychiatric services, their organisation, functioning and culture.

\section{Italian communities at a glance}

Italy is a country of 56995744 inhabitants (census of 21 0 ctober 2001) and its economy is the world's seventh largest in terms of gross domestic product (GDP) (World Bank, 2003). It has the world's fifth highest life expectancy at birth (76.9 years for men and 83.3 years for women) (World Health 0 rganization, 2003).

Administratively, the country is divided into 20 regions and 109 provinces. Because of its historical fragmentation until reunification in 1870 , striking social and economic 
differences persist across the nation. Per capita income, economic activities, distribution of wealth, rates of unemployment and the development of welfare services are still very different in northern-central compared with so uthern regions. In acknowledgement of this, a policy of devolution is now transferring most administrative powers to regional councils; notably, this includes all functions related to planning and management of health services. This explains the remarkable differences in models and implementation of psychiatric services, whose landscape has been described as 'patchy and confused' (Freeman et al, 1985).

Although rapid demographic changes are occurring (in particular, massive immigration is compensating for a decrease in the native population, which presently has a low birth rate), Italian so ciety is still based on strong family links and demographic stability. Recent comparative studies (Warner et al, 1998; Fioritti et al, 2002) have shown that over $70 \%$ of patients with psychosis live with their family, in accommodation they own and in which they have typically lived for about 20 years. Patients are usually well protected from certain psychosocial stresses (e.g. housing and financial problems) but quite dependent on significant others, whose involvement in the care process is almost always required. Families are fundamental stakeholders in health administration and their associations have become very influential on national and regional mental health policies (e.g. becoming providers of mental health services or supporting bills to reform current legislation).

\section{Health care and psychiatric services}

Italy has had a N ational Health Service (N HS) since 1978, when a comprehensive public health policy was adopted. The N HS absorbs about $6 \%$ of the nation's GDP, while an additional $2-3 \%$ of it is spent on private health services. About $5 \%$ of N HS resources are allocated to child and adult psychiatry, excluding services for drug misuse and learning disabilities. It is generally held that the implementation of the N HS has achieved good results in the northern regions but failed most of its promises in the south, mostly because of pre-existing social and economic factors (Putnam, 1993).

The N H S is organised through 401 local health trusts (aziende unità sanitarie locali - AUSL), each caring for a geographically defined population of $200000-500000$ inhabitants. They have full economic accountability and reasonable autonomy in planning, managing and evaluating services. Each AUSL has one mental health department (dipartimento di salute mentale - DSM ), which provides comprehensive psychiatric care for the local population and manages on a unitary basis the full set of necessary services (as stipulated within national policy documents):

o community mental health centres (CMHCs)

O day-hospital/day-care rehabilitation centres

o psychiatric wards within a general hospital (servizio psichiatrico di diagnosi e cura - SPDC)

o non-hospital residential medium- and long-term facilities (N H RF).

Regional and local differences can be found as to standards (i.e. number of beds, allocation of resources to each unit within the department), integration of private services within the DSM and integration with child psychiatry, drug misuse and learning disabilities services.

This system is the end-point of a process started by Law 180 of 1978, which had five key effects:

o all mental hospitals were gradually phased out, with a halt to all new admissions

o general hospital psychiatric wards (SPDC S) were established, each with a maximum of 15 beds

o severe limitations were set on procedures for compulsory admissions and on their length (maximum 7 days, renewable weekly)

o the CMHCs were established to provide psychiatric care to geographically defined areas

o all new and old public psychiatric services were integrated within the N HS.

The 1980s saw the establishment of the CMHCs, the deinstitutionalisation of patients from the mental hospitals, who were usually moved into small N HRFs, and the establishment of the network of SPD C s by the general hospitals. The 1990s saw the establishment of the coordination of all these facilities under the DSM and the adaption of existing services to the new chronic population that was emerging. O nly in 1999 were the last mental hospitals closed, thereby bringing a 21-year process to an end. A critical issue of the 1990 s was also the integration of economic and quality assurance elements within the management of clinical teams, as required by policies and laws affecting all health services. Throughout that decade, the actual number of professionals employed by the N HS in psychiatry decreased by about 10\% (from 34000 in 1992 to 30711 in 2002) and so did the number of psychiatrists (from 6276 in 1992 to 5561 in 2002).

Italian psychiatry today represents a multifaceted and complex system (see Table 1). CMHCs are well established all over the nation; their multi-professional teams ensure general psychiatric evaluation and care, and often good assertive outreach. These services are grounded in an interesting mix of phenomenology, psychodynamics, and clinical and social psychiatry. The actual number of hospital beds and facilities is among the lowest in Europe. 0 ne recent comparison of the psychiatric laws of all European U nion countries acknowledged that the Italian law and

Table 1. The composition of Italian mental health services

\begin{tabular}{lrc}
\hline & Number & Rates per 100000 population \\
\hline $\begin{array}{l}\text { Community mental health centres } \\
\text { Psychiatric wards in the general hospital }\end{array}$ & 707 & 1.24 \\
$\quad$ Number & 321 & 0.56 \\
$\quad$ Beds & 3997 & 7.01 \\
Private clinics & & \\
$\quad$ Number & 56 & 0.09 \\
$\quad$ Beds & 3950 & 6.92 \\
Non-hospital residential facilities & & \\
$\quad$ Number & 1370 & 2.40 \\
$\quad$ Beds & 17138 & 30.06 \\
Day centres & 921 & 1.61 \\
\hline
\end{tabular}

Data from Ministero della Salute (2001) and, for the non-hospital residential facilities, de Girolamo et al (2002) (these facilities comprise supported housing with four or more beds with any degree of staff supervision, therapeutic communities and facilities set up as alternative to mental hospitals). 
system pose the lowest level of formal coercion over the patient (Fioritti, 2002). In seven regions, additional hospital beds are acquired from private clinics under 'allowance schemes', but the total number ofbeds in hospitals remains low. The area of medium- to long-term N H RFs saw a large expansion during the 1990s and now accounts for more beds than the hospital sector (de Girolamo et al, 2002).

C hallenges currently on the agenda include: collabor-

Challenges

currently on the agenda include: collaboration with primary care; the integration with drug misuse services; and the integration (or reform) of the forensic psychiatry sector.

Italian psychiatry ranks ninth

internationally in terms of the number of papers published and eleventh in terms of their impact. ation with primary care; the integration with drug misuse services; and the integration (or reform) of the forensic psychiatry sector, which is still a separate system, run by the Ministry of Justice, with very few points of contact with the N HS (Fioritti \& Melega, 2000).

\section{Education and training}

Psychiatry is part of the compulsory undergraduate training of every medical student on a degree course in medicine and surgery at any Italian university. It is usually organised as formal teaching (i.e. lectures and seminars), and it is then followed by an oral examination.

Psychiatry is now taught in its own right at postgraduate level as well, having been separated from neurology in the mid-1970s, but still in the 1980s the psychological sciences had little place in medical curricula. At the beginning of the 1990s Italy had to conform to European educational standards and universities adapted very rapidly to these requirements. To become a psychiatrist, the student (who has already registered with the Medical Council before applying to the Psychiatry Residency School) must attend courses for four academic years and must discuss his/her own dissertation at the end of training. Today, residents are fully integrated within the teams of teaching psychiatric clinics or of public health services. They attend theoretical lessons and receive a broad range of practical experiences in general hospital and community psychiatry, consultation-liaison, psychotherapy, rehabilitation and research.

0 ther mental health professionals do not receive specific training before employment and their education is based on practical experience and educational programmes set up by their employers. In 2000 a formal system of continuing medical education based on credits was set up and has served to greatly improve local educational programmes at both public and private psychiatric institutions.

\section{Research}

Research in mental health has achieved mixed results. Italian psychiatry ranks ninth internationally in terms of the number of papers published and eleventh in terms of their impact (Fava \& Montanari, 1998); these contributions largely come from a few distinguished centres (Verona for social psychiatry and epidemiology, Pisa, Milan and Cagliari for biological psychiatry, Bologna for psychotherapy) (Fava $\&$ Tansella, 2002). This is not an adequate representation of the intensive national and international scientific life of Italian universities, scientific societies and DSMs. Some research projects whose formal bibliometric impact is low have none the less yielded very significant results and shown that good organisation and commitment can produce good research within very limited budgets (e.g. the 'Progres Project'; de G irolamo et al, 2002). Finally, Italian research teams are currently involved in all major collaborative studies financed by the European U nion in psychiatry (e.g. EUN O MIA and EQ O LISE).

\section{Professional bodies}

The Italian Psychiatric Association (Società Italiana di Psichiatria - SIP) has about 6000 members and has 25 thematic sections. It is very active and supports several educational and research programmes.

Important acknowledgements to Italian psychiatry have come from appointments to international bodies of highly representative psychiatrists: $\mathrm{Dr}$ Benedetto Saraceno is currently Director of Mental $H$ ealth and Substance D ependence at the World Health $O$ rganization in Geneva; and Professor Mario Maj is President of the European Association of Psychiatrists.

\section{Conclusions}

As early as 1950, Italian psychiatry was mentioned in international scientific papers for its obsolete and repressive institutions (Lemkau \& de Sanctis, 1950). This went on until the reform law of 1978. Deinstitutionalisation has probably met in Italy its more radical form and produced a complex and multifaceted system of community psychiatry which is now actively looking for international comparison.

\section{References}

de Girolamo, G., Picardi, A., Micciolo, R., et al (2002) Residential care in Italy: national survey of non-hospital facilities. British Journal of Psychiatry, 181, 220-225

Fava, G. A. \& Montanari, A. (1998) N ational trends in behavioural sciences. Psychotherapy and Psychosomatics, 67, 281301

Fava, G. A. \& Tansella, M. (2002) Gli autori ed i lavori italiani più citati nelle riviste internazionali di Psichiatria e Psicologia. Epidemiologia e Psichiatria Sociale, 11, 298-302.

Fioritti, A. (2002) Leggi e Salute Mentale: Panorama europeo delle legislazioni di interesse psichiatrico. Torino: Centro Scientifico Editore.

Fioritti, A. \& Melega, V. (2000) Psichiatria forense in Italia, una storia ancora da scrivere. [Italian forensic psychiatry: a story to be written.] Epidemiologia e Psichiatria Sociale, 9, 219226

Fioritti, A., Lo Russo, L. \& Melega, V. (1997) Reform said or done? The case of Emilia-Romagna within the Italian psychiatric context. American Journal of Psychiatry, 154, 9498.

Fioritti, A., Burns, T., Rubatta, P., et al (2002) Impact of the community on intensive community care. A comparative study of patient characteristics and inpatient service use in Bologna and London. International Journal of Mental Health, 31, 66-77.

Freeman, H. L., Fryers, T. \& Henderson, J. H. (1985) Mental Health Services in Europe. Ten Years On. Geneva: WHO.

Jones, K., Wilkinson, G. \& Craig, T. K. (1991) The 1978 Italian mental health law - a personal evaluation: a review. British Journal of Psychiatry, 159, 556-561.

Lemkau, P. V. \& de Sanctis, C. (1950) A survey of Italian psychiatry. American Journal of Psychiatry, 107, 401-408.

Mangen, S. (1989) The Italian psychiatric experience. International Journal of Social Psychiatry, 35, 3-6. 
Ministero della Salute (2001) Assistenza Psichiatrica in Italia. Rome: Ministero della Salute.

Mosher, L. R. (1982) Italy's revolutionary mental health law: an assessment. American Journal of Psychiatry, 139, 199-203.

Perris, C. \& Kemali, D. (1985) Focus on the Italian psychiatric reform: an introduction. Acta Psychiatrica Scandinavica Supplementum, 316, 9-14.

Putnam, R. D. (1993) Making Democracy Work. Civic Traditions in Modern Italy. Princeton, N J: Princeton U niversity Press.
Saraceno, B. \& Tognoni, G. (1989) Methodological lessons from the Italian psychiatric experience. International Journal of Social Psychiatry, 35, 98-109.

Warner, R., de Girolamo, G., Belelli, G., et al (1998) The quality of life of people with schizophrenia in Boulder, Colorado, and Bologna, Italy. Schizophrenia Bulletin, 24, 559-568.

World Bank (2003) Data from the website www.worldbank.org. World Health Organization (2003) Data from the website www.who.int

\section{The Association of European Psychiatrists' programme of itinerant CME courses}

\section{Mario Maj}

President, Association of European Psychiatrists; Clinica Psichiatrica Università, Largo Madonna delle Grazie, I - 80138 Napoli, Italy, email majmario@tin.it

ccording to the most recent data provided by the World Health 0 rganization (2001), there are presently in Europe more than 77000 psychiatrists, more than 46000 clinical psychologists active in the mental health field, more than 285000 psychiatric nurses, and more than 91000 social workers operating in the mental health sector. Are these professionals being adequately updated on recent clinical and service developments in mental health? What is the role of international channels (in particular, those of international professional associations) in this process? These are difficult questions to answer, in the absence of a European systematic survey (which, of course, would be a very worthwhile initiative). I try, however, to provide here a framework for a discussion of these issues, as a background to the presentation of the programme of itinerant educational courses run by the Association of European Psychiatrists (AEP).

\section{The main channels}

The main international channels of professional update in the mental health field are scientific meetings, traditional publications (i.e. professional journals, books and other printed materials), the internet and the direct channels used by drug companies.

\section{Scientific meetings}

A w ell-organised international meeting offers a variety of opportunities for update, from state-of-the-art lectures to workshops and educational courses. Several international meetings offer a programme of continuing medical education (CME) courses, with provision of credits.

The problem is, how ever, that the average European psychiatrist is often unable to afford the registration fee, so that his or her participation often depends on sponso rship by a drug company. This means that psychiatrists who do not have relationships with drug companies are penalised in their access to professionally relevant information. This is the case for virtually all psychiatrists of some European countries which are not very attractive to drug companies, in particular in eastern Europe. For instance, during the AEP CME course held in Almaty, Kazakhstan, on 6 June 2003, the participants were asked to complete a questionnaire concerning their previous participation in international psychiatric congresses. 0 ut of the 56 participants on the course, who were likely to represent a selected group of highly motivated psychiatrists, only two had ever participated in a W orld Congress of Psychiatry, and none had ever attended a Congress of the AEP, the European College of N europsychopharmacology (ECN P), the Collegium Internationale N europsychopharmacologicum (CIN P) or the American Psychiatric Association (APA). For those who may think that this is a marginal problem, it is useful to point out that the number of psychiatrists who are currently active in Kazakhstan is about 1000.

The European audience of international psychiatric meetings is represented by a restricted elite, mostly consisting of psychiatrists from 'group $A^{\prime}$ countries of the World Bank classification (i.e. those with the highest income per capita). Moreover, the participation of European mental health professionals other than psychiatrists is usually very limited.

Traditional publications

In psychiatry and related mental health disciplines, there are presently 89 jo urnals for which the Institute of Scientific Information reports an impact factor, of which 76 are produced in English. Most of these journals have an international distribution, but the vast majority and sometimes the to tality of their subscribers are from $\mathrm{N}$ orth America, Western Europe and Australia. The average European psychiatrist (especially from a group $B, C$ or D country) cannot afford the cost of the subscription to even one international journal. Moreover, in many European countries, libraries where international psychiatric journals can be found are few and difficult to access; in several group C or D European countries, no such library is available. Furthermore, many academic centres, even in group A European countries, are currently reducing the number of journals to which they subscribe.
For contributions to the Associations and Collaborations column, please contact Dr John Henderson: john.henderson53@ btopenworld.com

\section{atopenworld.com}

